\title{
Empirical 10-day sequential H. pylori eradication therapy could allow sparing of surgical intervention in chronic rhinosinusitis patients
}

Original Article

\author{
Mohamed A. Fatahalla', Ashraf A. Wahba ${ }^{1}$, Ali E. Hasaneen ${ }^{2}$ \\ ${ }^{1}$ Department of Otorhinolaryngology, Faculty of Medicine, Al-Azhar University, ${ }^{2}$ Department \\ of Internal Medicine, Faculty of Medicine, Banha University, Egypt
}

\section{ABSTRACT}

Objective: To determine the association between $\mathrm{H}$. pylori $(\mathrm{Hp})$ infection and subjective and objective chronic rhinosinusitis (CRS) parameters and to evaluate the effect of empirical Hp-eradication therapy using the 10-day sequential therapy (ST) on these parameters.

Patients and Methods: The study included 85 patients with manifestations of CRS, completed questionnaire to determine total subjective score (TSS) and underwent flexible nasal endoscopy, CT imaging, Urea Breath Test (UBT) and stool Hpantigen test. Patients were divided as $\mathrm{Hp}+$ or Hp-. All patients received 10-day ST and responders were re-evaluated 3-m later, but non-responders were given another 10-day ST course and re-evaluated. Non-responders to ST courses and responders who developed recurrent symptoms underwent FESS.

Results: 17 patients $(20 \%)$ were $\mathrm{Hp}+; 11$ in study and 6 in control groups. $12 \mathrm{Hp}+$ patients $(70.5 \%)$ and $23 \mathrm{Hp}$ - patients (33.8\%) responded to ST, $5 \mathrm{Hp}+$ patients were assigned to 2nd ST course and 48 patients underwent FESS. Three of $\mathrm{Hp}+$ patients responded to the 2 nd ST course, while two underwent FESS. Seven of the responders to $1^{\text {st }}$ ST course had recurred manifestations and underwent FESS, while 27 patients completed their follow-up uneventfully.

Conclusion: Hp infection may underlie chronicity of CRS and is correlated with severity scores. 10-day ST for Hp eradication is being effective within short-time trial. Empirical ST provided improvement of CRS scoring and spared or postponed surgery in about $31.8 \%$ of patients, irrespective of being $\mathrm{Hp}+$ or $\mathrm{Hp}$-, so it is advocated as a first-line trial for patients presenting with symptoms suggestive of CRS.

Key Words: Chronic rhinosinusitis, empirical course, h. pylori, outcome, sequential therapy.

Received: 30 April 2018, Accepted: 24 December 2018

Corresponding Author: Mohamed A. Fatahalla, MD, Department of Otorhinolaryngology, Faculty of Medicine, Al-Azhar University, Tel.: +966599141013, E-mail: mohamedfatahalla20018@gmail.com

ISSN: 2090-0740, March 2019 Vol.20, No.1

\section{INTRODUCTION}

Rhino-sinusitis (RS) is characterized by inflammation extending from nasal cavity mucosa into the paranasal sinuses $^{[1]}$. RS may be acute lasting up to 4 weeks or chronic lasts for $\geq 12$ weeks $^{[2]}$. Chronic rhinosinusitis (CRS) is a common and potentially debilitating disease characterized by inflammation of the sinus mucosa ${ }^{[3]}$ and can be diagnosed by presence of discolored rhinorrhea, postnasal drip, nasal obstruction, facial pressure or pain, or decreased sense of smell ${ }^{[4]}$.

Chronic or recurrent attacks of RS disease had many attributes, where Netkovski \& Shirgoska ${ }^{[5]}$ found about $10 \%$ of patients had chronic inflammation of paranasal sinuses were diagnosed with fungal rhinosinusitis. Also, Rowan et $a .^{[6]}$ reported that respiratory viruses were more commonly isolated from patients with CRS than healthy controls, moreover, respiratory viruses may induce symptom exacerbation in patients with CRS without nasal polypi than patients with nasal polypi Moreover, some aggravating features especially that inducing immunosuppression ${ }^{[7]}$ can cause nasal mucosal inflammation to linger for a long period, resulting in chronic or recurrent episodes ${ }^{[2]}$.

Bacterial colonization of the sinuses and its role in the pathogenesis of CRS is an ongoing area of research ${ }^{[3]}$. $\mathrm{H}$. pylori is gram-negative spiral organisms that colonizes the stomach and is characterized by aggressiveness and inducing epithelial damage ${ }^{[8]}$. The immune response to Hp importantly determines the pathogenesis of infection and the success of antibiotic eradication of the bacteria ${ }^{[9]}$. However, Hp could persist within the host despite a robust immune response and elicit an inflammatory response from host epithelia, resulting in the recruitment of immune cells which manifests as inflammation ${ }^{[10]}$. Moreover, multiple factors are responsible for $\mathrm{Hp}$ aggressiveness including cytotoxin-associated gene $\mathrm{A}^{[11]}$ and vacuolating cytotoxin $\mathrm{A}^{[12]}$ that thought to be associated with chronic inflammation and disease ${ }^{[10]}$. 
Direct and/or indirect mechanisms were involved in association between $\mathrm{Hp}$ and upper respiratory tract diseases, various studies over the past two decades have suggested such relationship ${ }^{[13]}$, where Saki et al..$^{[14]}$ detected heavy colonization of HP in adenoid tissue and middle ear, Nártová et al ${ }^{[15]}$ and Ochung'o et al.$^{[16]}$ also detected HP in tonsil specimens after tonsillectomy for chronic tonsillitis and sleep apnea syndrome patients.

\section{Objectives}

The current study tried to determine the association between Hp infection and subjective and objective CRS severity parameters and to evaluate the effect of empirical Hp-eradication therapy using the 10-day sequential therapy (ST) on CRS severity parameters

\section{Design}

Prospective comparative double-blinded observational study

\section{PATIENTS AND METHODS}

The study was conducted in Jeddah Clinic Hospital Kandara (JCHK), Kingdom Saudi Arabia (KSA) since Sep 2015 till March 2017 to allow a minimum follow-up period of 6 months for the last case included in the study. Study protocol was approved by the Local Ethical Committee. The study intended to include patients presenting to outpatient clinic of otorhinolaryngology with symptoms suggestive of CRS. CRS was diagnosed according to criteria defined by the Rhinosinusitis Task Force ${ }^{[17]}$, patients have $\geq 2$ major or one major and $\geq 2$ minor factors (Table 1 ) for $\geq 12$ weeks despite of antibiotic therapy for 4 weeks and were assigned to FESS were collected as Study group. Patients who did not fulfill the inclusion criteria were included as positive control group.
All patients were asked to complete a questionnaire to determine the total subjective score (TSS). The questionnaire included 8 symptoms need to be scored concerning intensity, as 0 : no symptoms, 1: mild, 2 : moderate, 3 : severe, and frequency as $0:$ never, 1: rare, 2: sometimes, 3: often. Each of symptoms including: blocked nose, nasal discharge, post-nasal drip, sneezing, headache, cough, decreased sense of smell and facial swelling, were evaluated to give a TSS ranging between no manifestations $(=0)$ and maximum distressful manifestations $(=48)^{[18]}$.

Then, patients were referred to Internal Medicine Department and to undergo full history taking and complete clinical examination to fulfill inclusion and exclusion criteria. Exclusion criteria included CRS with polyposis, presence of dyspeptic manifestations, history of previous therapy for Hp, peptic ulcer, immunosuppressive diseases, endocrinopathy, or previous surgery for gastro-esophageal reflux. Also, patients with hepatic or gastrointestinal ulcerative diseases or maintained on immunosuppressive therapy for any indication were excluded from the study.

All patients enrolled in the study underwent rigid nasal endoscopy and endoscopic findings were graded bilaterally according to Lund-Kennedy scoring system with a score range of 0-12 and diagnostic cutoff point score of $>2^{[19]}$. Thereafter, patients had para-nasal sinuses CT imaging that was evaluated according to Lund-Mackay scale ${ }^{[20]}$ with a score range of 0-24 points, and the higher the score the greater severity of the disease.

\section{Steps and Options of Management Policy}

1. All patients who were $\mathrm{Hp}+$ or $\mathrm{Hp}$ - received the 10day sequential Hp eradication therapy ${ }^{[21]}$, to safeguard against any fallacies of the result of Hp diagnostic tests and presence of subacute or dormant infection and to fulfill the criteria of the study as observational

Table 1: Factors associated with diagnosis of rhinosinusitis ${ }^{[17]}$

\begin{tabular}{ll}
\hline Major Factors & Minor Factors \\
\hline Facial pain/pressure & Headache \\
Nasal obstruction/blockage & Fever (all non-acute rhinosinusitis) \\
Nasal discharge/purulence/discolored postnatal drainage & Halitosis \\
Hyposmia/anosmia & Fatigue \\
Purulence in nasal cavity on examination & Dental pain \\
Fever (acute rhinosinusitis only) & Cough \\
\hline
\end{tabular}

Data are presented as numbers; percentages are in parenthesis 
double-blinded study. The 10-day sequential therapy consisted of proton pump inhibitor (omeprazole 20 $\mathrm{mg}$ twice daily) for 5 days followed by omeprazole (20 mg twice daily), clarithromycin $(500 \mathrm{mg}$ twice daily) and metronidazole (500 $\mathrm{mg}$ twice daily) for another 5 days. At the end of the 10-day treatment course, patients were re-evaluated for TSS endoscopic disease scoring.

2. Patients who showed significant improvement concerning CRS manifestations and scoring were considered as Responders and were followed up for 3-m duration and re-evaluated.

3. Patients who showed non-significant improvement (Non-responders); if they were still $\mathrm{Hp}+$, another 10-day Hp-eradication therapy course was given and were re-evaluated thereafter.

4. Non-responders to the $1^{\text {st }} 10$-day course who were $\mathrm{Hp}$-, non-responders to the $2^{\text {nd }} 10$-day course and responders who developed recurred symptoms during follow-up; all underwent functional endoscopic sinus surgery (FESS) without giving another course of medical treatment for CRS depending on the inclusion criteria that all patients had received previous courses of medical treatment with no improvement.

\section{Investigations}

\section{Urea breath test (UBT)}

Urea breath test was performed using the Heliprobe 14C UBT (Kibion Heli-probe System, Stockholm, Sweden). Heliprobe $1 \mu$ Curie $14 \mathrm{C}$ capsule was given, after 10 min, patients were asked to blow (only exhaled) into the Heliprobe breath-Card until the card indicator of the breath card changed from orange to a yellow color. Then, the Breath-Card was inserted into the small desktop GM-counter (Heli-probe Analyzer). The results were graded as Grade 0: not infected; Grade 1: borderline; and Grade 2: infected ${ }^{[22]}$. The amount of $14 \mathrm{C}$ contained per capsule (one micro-curie) is safe as the provided radioactivity equals $1 / 300$ of total radiation received in one year from the environment ${ }^{[23]}$.

\section{H. pylori stool antigen test:}

H. pylori stool antigen test (Hp-SAT) was performed using One-Step H. pylori Antigen RapiCardTM Insta Test (Cortez Diagnostics, Inc, Califa St, Woodland Hills, California, USA) according to the manufacturer's instructions. Briefly, small stool specimens were collected from three different parts of the stool sample, vigorously shacked in a vial with diluent, allowed to sediment for two minutes, and then 2-3 drops of supernatant were put into the sample well of the test cassette. If the sample contains $\mathrm{H}$. pylori antigens, it will bind to the antibody coated on red colloidal gold particles to form antigen-antibody-gold complexes which move on the nitrocellulose membrane by capillary action toward the test line region ( $\mathrm{T}$ region) on which $\mathrm{H}$. pylori specific antibodies are immobilized. A second red control line will always appear in $\mathrm{C}$ region to indicate that the test has been correctly performed and the test device functions properly. Appearance of two red lines at $\mathrm{T}$ and $\mathrm{C}$ regions indicated that the test is positive, i.e. $\mathrm{H}$. pylori antigen is present. Appearance of red line in $\mathrm{C}$ region only indicates negative test, but if no color appeared at $\mathrm{C}$ region, the test was considered as invalid ${ }^{[24]}$.

\section{Study outcome}

1. The frequency of co-incidence between Hp infection and nasal sinuses disease and its relation to disease severity.

2. The effect of Hp eradication therapy as a sole line of treatment on $\mathrm{Hp}$ infection, disease severity as judged by TSS and nasal endoscopy and need for surgical interference.

3. The value of empirical Hp eradication therapy on sinus disease severity as judged by outcome of $\mathrm{Hp}$ patients and recurrence rate for responders to $\mathrm{Hp}$ eradication therapy.

4. The frequency of spared surgery for responders to Hp eradication therapy and its relation to baseline findings.

\section{Statistical analysis}

Obtained data were presented as mean $\pm \mathrm{SD}$, ranges, numbers and ratios. Results were analyzed using One-way ANOVA with post-hoc Tukey HSD Test and Chi-square test (X2 test). Statistical analysis was conducted using the IBM SPSS (Version 23, 2015) for Windows statistical package. $P$ value $<0.05$ was considered statistically significant.

\section{RESULTS}

The study included 114 patients eligible for evaluation; 29 patients were excluded and 85 patients were included in the study. Fifty-one patients fulfilled the inclusion criteria in Study group and 34 patients were included in the control group (Figure 1). Demographic data showed nonsignificant difference between both groups, while clinical data significantly different between patients of both groups (Table 2). 


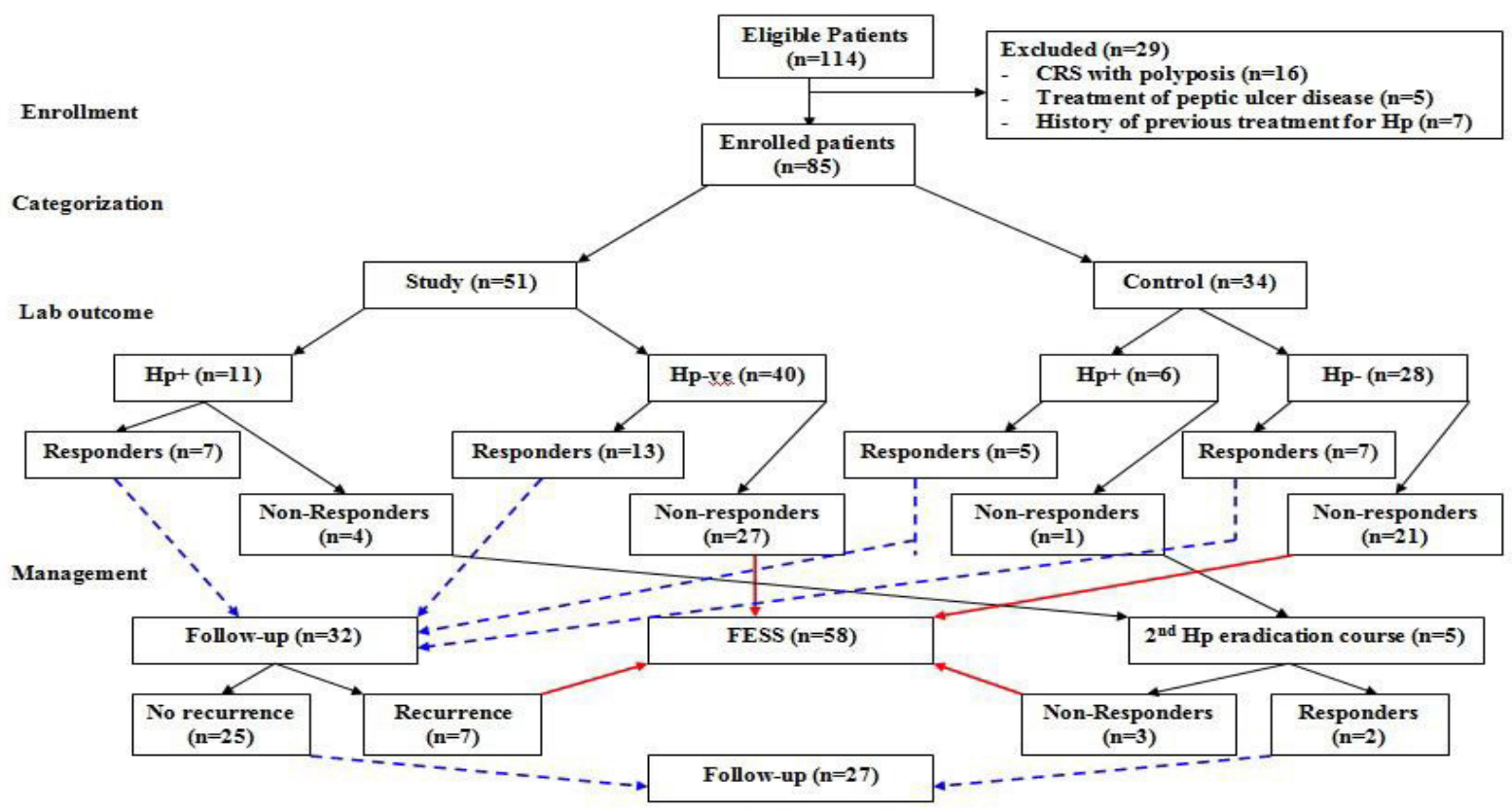

Fig. 1: Study Flowchart

Table 2: Demographic and clinical data of studied patients

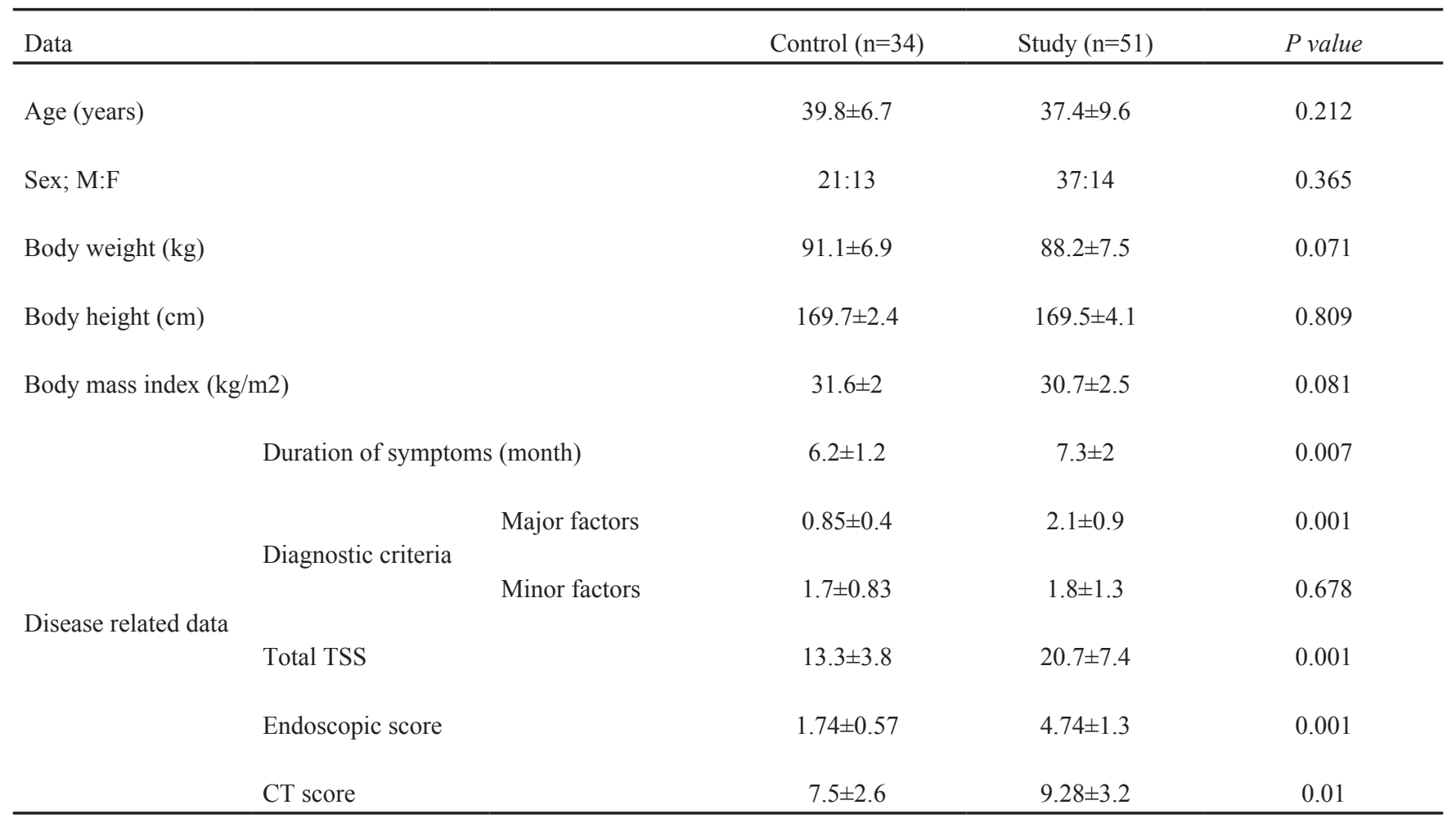

Data are presented as mean \pm SD; TSS: Total subjective score; $\mathrm{p}<0.05$ indicates significant difference; $\mathrm{p}>0.05$ indicates non-significant difference 
Seventeen patients $(20 \%)$ were $\mathrm{Hp}+$, while 68 patients were Hp-; 11 in study and 6 in control groups. Presence of $\mathrm{Hp}$ infection positively correlated with baseline total TSS, endoscopic score and CT score in all studied patients. Moreover, presence of $\mathrm{Hp}$ infection showed positive significant correlation of disease duration in patients of study group, while the relation was non-significant in patients of control group (Table 3).

Table 3: correlation coefficient between presence of $\mathrm{Hp}$ infection and clinical data of studied patients

\begin{tabular}{lcccc}
\hline \multirow{2}{*}{ Group Variable } & \multicolumn{3}{c}{ Control $(\mathrm{n}=34)$} & \multicolumn{3}{c}{ Study $(\mathrm{n}=51)$} \\
& $\mathrm{r}$ & $\mathrm{p}$ & $\mathrm{r}$ & $\mathrm{p}$ \\
\hline Duration of symptoms (month) & 0.304 & 0.030 & 0.311 & 0.074 \\
Total TSS & 0.349 & 0.043 & 0.333 & 0.017 \\
Endoscopic score & 0.354 & 0.040 & 0.318 & 0.023 \\
CT score & 0.389 & 0.023 & 0.282 & 0.045 \\
\hline
\end{tabular}

r: Pearson's correlation coefficient; TSS: Total subjective score; $\mathrm{p}<0.05$ indicates significant difference; $\mathrm{p}>0.05$ indicates non-significant difference

Twelve of $\mathrm{Hp}+$ patients $(70.5 \%)$ and interestingly, 20 of Hp- patients (29.4\%) responded to the sequential Hp eradication therapy, concerning CRS manifestations, and these 32 patients were assigned for follow-up. On the other hand, 53 failed to respond to the sequential Hp eradication therapy; 5 of $\mathrm{Hp}+$ patients and were assigned to a $2^{\text {nd }}$ course of $\mathrm{Hp}$ eradication therapy, while the remaining 48 patients underwent FESS, 27 patients of study and 21 of control groups. At the end of the 2nd course of Hp eradication therapy, 3 patients responded to treatment and were assigned for follow-up, while two patients failed to respond to the $2^{\text {nd }}$ course and underwent FESS. Unfortunately, 7 of the 32 responders to 1 st course had recurred manifestations and underwent FESS, while 25 patients completed their follow-up uneventfully (Figure 1).

Patients of control group had significantly lower TSS and endoscopic score compared to patients of study group; both before and after receiving Hp-eradication therapy. Responders of both groups showed significantly lower TSS and endoscopic score compared to non-responders with significantly lower scores in control versus study group (Table 4).

\section{DISCUSSION}

Patients enrolled in this study were surveyed and categorized as $\mathrm{H}$. pylori positive $(\mathrm{Hp}+)$ or negative (Hp-) using urea breath test (UBT) and Hp stool antigen (HpSA) test for being noninvasive effective diagnostic tests. In line with the applied methodology, the results obtained by Tiwari et al. ${ }_{0}^{[25]}$ indicated that UBT may be employed after completion of eradication therapy to assure infection eradication and Ferwana et al. ${ }^{[26]}$, (2015) out of literature meta-analysis concluded that UBT has high diagnostic accuracy for detecting Hp infection. Concerning HpSA test, Douraghi et al. ${ }^{[27]}$ reported that HpSA test is sensitive, non-invasive, valid screening modality for $\mathrm{Hp}$ as it detects the specific antigens shed during active infections, has less crossreactivity than serological antibodies detection tests. Recently, Diaconu et al. ${ }^{[28]}$ documented that UBT and HpSA can be used to confirm Hp infection eradication and should be performed at least 4 weeks after the completion of therapy.

The detection rate of Hp infection among studied patients who were free of any dyspeptic manifestations was $20 \%$, thus indicating the possibility of subclinical HP infection in asymptomatic people. Similarly, Taddesse et al. ${ }^{[29]}$, Mansour et al. ${ }^{[30]}$ and Bunchorntavakul \& Atsawarungruangkit ${ }^{[31]}$ reported prevalence rates of $\mathrm{Hp}$ infection in non-dyspeptic patients of $39 \%, 45 \%$ and $27.1 \%$, respectively.

Concerning studied CRS patients, the systemic detection of Hp infection in patients with a local disease and the reported positive significant correlation between positivity of Hpdetection tests and presence and severity of clinical subjective and objective data in both patients and controls assured that previously reported on examination of local tissue specimens taken from CRS patients for presence $\mathrm{Hp}$, where Ozdek et $a l_{0^{[32]}}$ and Morinaka et al. ${ }^{[33]}$ detected Hp DNA or Hp 16S ribosomal RNA gene, respectively, in nasal and maxillary sinus tissue specimens of patients with CRS. Also, Koc et al. ${ }^{[34]}$ and Cvorovic et al.$^{[35]}$ using urease test could detect HP in nasal polyp specimens obtained from CRS patients but not in any patient with concha bullosa and assured these results by histochemical analysis. Thereafter, Nikakhlagh et al. ${ }^{[36]}$ isolated Hp DNA using PCR in $18 \%$ of specimens of patients with CRS, but in $4 \%$ of patients with concha bullosa without inflamed sinuses.

Table 4: Post-treatment TSS and endoscopic score of patients of both groups categorization according to response to Hp eradication therapy

\begin{tabular}{|c|c|c|c|c|}
\hline Group & Response & Time & TSS & Endoscopic score \\
\hline \multirow{4}{*}{ Control $(\mathrm{n}=34)$} & \multirow{2}{*}{ Responders } & Baseline & $11.6 \pm 3.4$ & $1.8 \pm 0.6$ \\
\hline & & Post-T & $7.3 \pm 1.6^{* \dagger} \dagger$ & $1.2 \pm 0.6 * \dagger$ \\
\hline & \multirow{2}{*}{ Non-responders } & Baseline & $14.2 \pm 3.7$ & $1.7 \pm 0.6$ \\
\hline & & Post-T & $12.5 \pm 3.7$ & $1.5 \pm 0.6$ \\
\hline \multirow{4}{*}{ Study $(\mathrm{n}=51)$} & \multirow{2}{*}{ Responders } & Baseline & $23.3 \pm 6.3 \$$ & $5 \pm 1.4 \hbar$ \\
\hline & & Post-T & $14.3 \pm 3.6 * \dagger \dagger$ & $2.9 \pm 1.2 *+\dagger$ \\
\hline & \multirow{2}{*}{ Non-responders } & Baseline & $19.1 \pm 7.6 \$$ & $4.6 \pm 1.2 \ddagger$ \\
\hline & & Post-T & $17.1 \pm 5.2 \ddagger$ & $4 \pm 1.3 \%$ \\
\hline
\end{tabular}

Data are presented as mean \pm SD; TSS: Total subjective score; $*$ : significant difference versus baseline score; $\dagger$ : significant difference versus non-responders; †: significant difference versus control group 
All patients, irrespective of the results of diagnostic tests, received empirical Hp-eradication therapy in the form of 10-day sequential therapy (ST) without any additive specific therapy for nasal sinus disease. In lie with the choice of the 10-day Hp sequential therapy not the standard triple therapy, Kim et al.$^{[37,38]}$ documented that ST achieved better eradication rates than triple therapy as a first-line therapy for Hp eradication. Moreover, Nyssen et al ${ }^{\left[{ }^{[39]}\right.}$ out of meta-analysis concluded that ST was more effective than standard triple therapy for $\mathrm{Hp}$, especially when standard triple therapy was given for only seven days. Recently, Chang et al. ${ }^{[40]}$, documented that the eradication rate of triple therapy was below the recommended threshold, while ST could be effective and tolerable as first-line Hp eradication therapy. In support of the use of ST as empirical therapy, Martos et al.$^{[41]}$ and Miftahussurur $\&$ Yamaoka $^{[42]}$ reported that sequential regimens are now replacing standard triple therapies as empirical first-line treatment and eradication rate was significantly higher than empirical standard triple therapy.

Thirty-five patients $(41.2 \%)$ responded to the empirical ST for Hp manifested as significantly reduced TSS and endoscopic scoring including 12 of $\mathrm{Hp}+$ patients $(70.5 \%)$ and interestingly, 23 of Hp- patients (33.8\%). The outcome of medical treatment of $\mathrm{Hp}$ as a supposed cause for chronicity and failure to response to conventional CRS therapy indicated a definite role of $\mathrm{Hp}$ in induction of chronicity through downregulation of immune system and flaring up of local inflammatory reaction. To our knowledge, no previous study evaluated the effect of Hp eradication therapy alone on clinical manifestations of CRS; however, these results coincided with and supported that previously reported in literature concerning coupling of surgical treatment of CRS with Hp-eradication therapy where Dinis et al. ${ }^{[43]}$ documented complete symptom relief after surgical sphenoidotomy and treatment with anti-H pylori medication. Jelavic et al. ${ }^{[44]}$ reported that CRS patients with HP positive samples have statistically significant greater improvement of postoperative endoscopic scores. Nikakhlagh et al. ${ }^{[36]}$ reported a significant correlation between CRS and presence of HP in Sino nasal mucosa and documented that this relationship may reflect the role of $\mathrm{HP}$ as one of the pathogenic factors in the development of CRS.

\section{CONCLUSION}

H. pylori infection could occur in asymptomatic patients free of dyspeptic manifestations. Hp infection may underlie chronicity of CRS and is positively correlated with subjective and objective severity scores. Ten-day ST for $\mathrm{Hp}$ eradication is appropriate for being effective within short-time trial. Empirical ST provided improvement of CRS scoring and spared or postponed surgery in about $31.8 \%$ of patients, irrespective of being $\mathrm{Hp}$ positive of negative, so it is advocated as a first-line trial for patients presenting with symptoms suggestive of CRS. However, wider scale studies with long-duration follow-up were required to assure the surgery sparing effect of empirical ST.

\section{Limitation}

The study relied on detection of Hp infection using Urea breath test and $\mathrm{H}$. pylori stool antigen test due shortage of more accurate diagnostic tests as PCR in hospital lab.

\section{ACKNOWLEDGEMENT}

The authors acknowledge the staff members of hospital lab for their effort in completion of this work.

\section{CONFLICT OF INTEREST}

The authors show no Conflict of interest.

\section{REFERENCES}

1. Ortiz E, Altemani A, Vigorito AC, Sakano E, Nicola EM: Rhinosinusitis in hematopoietic stem cell-transplanted patients: influence of nasosinus mucosal abnormalities? Stem Cell Res Ther. 2014; $5(6): 133$

2. Shoup J: Management of adult rhinosinusitis. Nurse Pract. 2011; 36(11):22-6; quiz 26-7.

3. Joss TV, Burke CM, Hudson BJ, Darling AE, Forer M, Alber DG, Charles IG, Stow NW: Bacterial Communities Vary between Sinuses in Chronic Rhinosinusitis Patients. Front Microbiol. 2016; 6:1532.

4. Sarber KM, Dion GR, Weitzel EK, McMains KC: Approaching chronic sinusitis. South Med J. 2013; 106(11):642-8.

5. Netkovski J, Shirgoska B: Fungal rhinosinusitis. Prilozi. 2012; 33(1):187-97.

6. Rowan NR, Lee S, Sahu N, Kanaan A, Cox S, Phillips CD, Wang EW: The role of viruses in the clinical presentation of chronic rhinosinusitis. Am J Rhinol Allergy. 2015; 29(6):e197-200.

7. Justice JM, Sleasman JW, Lanza DC: Recalcitrant rhinosinusitis, innate immunity, and mannosebinding lectin. Ann Otol Rhinol Laryngol. 2015; 124(2):102-6.

8. Chowdhury R: Host cell contact induces furdependent expression of virulence factors CagA and VacA in Helicobacter pylori. Helicobacter. 2014; 19(1):17-25. 
9. Skvarc M, Kopitar AN, Kos J, Obermajer N, Tepes B: Differences in the antigens of Helicobacter pylori strains influence on the innate immune response in the in vitro experiments. Mediators Inflamm. 2014; 2014:287531.

10. Gaddy JA, Radin JN, Cullen TW, Chazin WJ, Skaar EP, Trent MS, Algood HM: Helicobacter pylori Resists the Antimicrobial Activity of Calprotectin via Lipid A Modification and Associated Biofilm Formation. MBio. 2015; 6(6):e01349-15.

11. Buti L, Spooner E, Van der Veen AG, Rappuoli R, Covacci A, Ploegh HL: Helicobacter pylori cytotoxin-associated gene A (CagA) subverts the apoptosis-stimulating protein of p53 (ASPP2) tumor suppressor pathway of the host. Proc Natl Acad Sci U S A. 2011; 108(22):9238-43.

12. Palframan SL, Kwok T, Gabriel K: Vacuolating cytotoxin A (VacA), a key toxin for Helicobacter pylori pathogenesis. Front Cell Infect Microbiol. 2012; 2:92.

13. Kariya S, Okano M, Nishizaki K: An association between Helicobacter pylori and upper respiratory tract disease: fact or fiction? World J Gastroenterol. $2014 ; 20(6): 1470-84$

14. Saki N, Samarbaf Zadeh AR, Sheikhpour Jonaky R, Noori SM, Kayedani GA, Nikakhlagh S: The Prevalence Rate of Helicobacter pylori Infection in, Chronic Otitis Media With Effusion Patients. Jundishapur J Microbiol. 2014; 7(3):e15694.

15. Nártová E, Kraus J, Pavlík E, Lukeš P, Katra R, Plzák J, Kolářová L, Sterzl I, Betka J, Astl J: Presence of different genotypes of Helicobacter pylori in patients with chronic tonsillitis and sleep apnoea syndrome. Eur Arch Otorhinolaryngol. 2014; 271(3):607-13.

16. Ochung'o OP, Mugwe P, Masinde P, Waweru W: Prevalence of H. Pylori in Tonsillar Tissue of Patients with Chronic Recurrent Tonsillitis Using Rapid Urease Test in a Tertiary Referral Hospital in Sub Saharan Africa. Indian J Otolaryngol Head Neck Surg. 2015; 67(3):223-6.

17. Report of the Rhinosinusitis Task Force Committee Meeting. Alexandria, Virginia, August 17, 1996. Otolaryngol Head Neck Surg 1997;117(3 Pt 2):S1-68.

18. Baudoin T, Kalogjera L, Geber G, Grgić M, Cupić H, Tiljak MK: Correlation of histopathology and symptoms in allergic and non-allergic patients with chronic rhinosinusitis. Eur Arch Otorhinolaryngol. 2008; 265(6):657-61.
19. Lund VJ, Kennedy DW: Quantification for staging sinusitis. International Conference on Sinus Disease: Terminology, Staging, Therapy. Ann Otol Rhinol Laryngol Suppl, 1995; 104 (suppl): 17-21.

20. Lund VJ, Mackay IS: Staging in rhinosinusitis. Rhinology 1993; 31:183-4.

21. Seddik H, Ahid S, El Adioui T, El Hamdi FZ, Hassar M, Abouqal R, Cherrah Y, Benkirane A: Sequential therapy versus standard tripledrug therapy for Helicobacter pylori eradication: a prospective randomized study. Eur $\mathrm{J}$ Clin Pharmacol. 2013; 69(9):1709-15.

22. Hamlet AK, Erlandsson KI, Olbe L, Svennerholm AM, Backman VE, Pettersson AB: A simple, rapid, and highly reliable capsule-based $14 \mathrm{C}$ urea breath test for diagnosis of Helicobacter pylori infection. Scand J Gastroenterol. 1995; 30(11):1058-63.

23. Di Silvio M, Larisch J, Dibildox M, Almaguer I, Gitler R, Dehesa M, Ramírez-Barba EJ: Breath tests as a noninvasive diagnostic method in Helicobacter pylori infection. Rev Gastroenterol Mex. 1998;63(3):135-42.

24. Hu F, Cheng H, Li J: Evaluation and comparison of the Helicobacter pylori stool antigen test and the gastric mucosal antigen test. Zhonghua Yi Xue Za Zhi. 2000; 80(11):820-2.

25. Tiwari BP, Nistala S, Patil SP, Kalgutkar DP, Jaychandran N, Chander H, Basu S: Evaluation of the (14)C-urea breath test using indigenously produced (14)C-urea capsules and a modified technique for trapping exhaled breath: a pilot study. Nucl Med Commun. 2014; 35(3):325-30.

26. Ferwana M, Abdulmajeed I, Alhajiahmed A, Madani W, Firwana B, Hasan R, Altayar O, Limburg PJ, Murad MH, Knawy B: Accuracy of urea breath test in Helicobacter pylori infection: meta-analysis. World J Gastroenterol. 2015; 21(4):1305-14.

27. Douraghi M, Nateghi Rostami M, Goudarzi $\mathrm{H}$, Ghalavand Z: Comparison of stool antigen immunoassay and serology for screening for Helicobacter pylori infection in intellectually disabled children. Microbiol Immunol. 2013; 57(11):772-7.

28. Diaconu S, Predescu A, Moldoveanu A, Pop CS, Fierbinţeanu-Braticevici C: Helicobacter pylori infection: old and new. J Med Life. 2017;10(2): 112-117. 
29. Taddesse G, Habteselassie A, Desta K, Esayas S, Bane A: Association of dyspepsia symptoms and Helicobacter pylori infections in private higher clinic, Addis Ababa, Ethiopia. Ethiop Med J. 2011; 49(2):109-16.

30. Mansour MM, Al Hadidi KhM, Omar MA: Helicobacter pylori and recurrent abdominal pain in children: is there any relation? Trop Gastroenterol. 2012; 33(1):55-61.

31. Bunchorntavakul C, Atsawarungruangkit A: Prevalence of asymptomatic gastroduodenal lesions and Helicobacter pylori infection in kidney transplant candidates. J Med Assoc Thai. 2014; 97 Suppl 11:S62-8.

32. Ozdek A, Cirak MY, Samim E, Bayiz U, Safak MA, Turet S: A possible role of Helicobacter pylori in chronic rhinosinusitis: a preliminary report. Laryngoscope. 2003; 113(4):679-82.

33. Morinaka S, Ichimiya M, Nakamura H: Detection of Helicobacter pylori in nasal and maxillary sinus specimens from patients with chronic sinusitis. Laryngoscope. 2003; 113(9):1557-63.

34. Koc C, Arikan OK, Atasoy P, Aksoy A: Prevalence of Helicobacter pylori in patients with nasal polyps: a preliminary report. Laryngoscope. 2004; 114(11):1941-4.

35. Cvorovic L, Brajovic D, Strbac M, Milutinovic Z, Cvorovic V: Detection of Helicobacter pylori in nasal polyps: preliminary report. J Otolaryngol Head Neck Surg. 2008; 37(2):192-5.

36. Nikakhlagh S, Samarbafzadeh AR, Jahani M, Poostchi H, Kayedani GA, Naghashpoor M, Saki $\mathrm{N}$ : Determining the Role of Helicobacter pylori in Chronic Sinus Infections Using the Polymerase Chain Reaction. Jundishapur J Microbiol. 2015; 8(3):e20783.

37. Kim SB, Lee SH, Kim KO, Jang BI, Kim TN: Tenday Sequential Therapy versus Bismuth Based Quadruple Therapy as Second Line Treatment for Helicobacter pylori Infection. Korean J Gastroenterol. 2015; 66(5):261-7.
38. Kim JS, Kim BW, Hong SJ, Kim JI, Shim KN, Kim JH, Baik GH, Kim SW, Song HJ, Kim JH: Sequential Therapy versus Triple Therapy for the First Line Treatment of Helicobacter pylori in Korea: A Nationwide Randomized Trial. Gut Liver. 2016; 10(4):556-61.

39. Nyssen OP, McNicholl AG, Megraud F, Savarino V, Oderda G, Fallone CA, Fischbach L, Bazzoli F, Gisbert JP: Sequential versus standard triple firstline therapy for Helicobacter pylori eradication. Cochrane Database Syst Rev. 2016; (6):CD009034.

40. Chang JY, Shim KN, Tae CH, Lee KE, Lee J, Lee KH, Moon CM, Kim SE, Jung HK, Jung SA: Triple therapy versus sequential therapy for the first-line Helicobacter pylori eradication. BMC Gastroenterol. 2017; 17(1):16.

41. Martos M, Bujanda L, Salicio Y, Sarasqueta C, Ibarra B, Mendarte U, Fernández-Reyes M, Cosme A: Clarithromycin for first-line treatment of Helicobacter pylori infection after culture in highresistance regions. Eur J Gastroenterol Hepatol. 2014; 26(12):1380-4.

42. Miftahussurur M, Yamaoka Y: Appropriate firstline regimens to combat Helicobacter pylori antibiotic resistance: an Asian perspective. Molecules. 2015; 20(4):6068-92.

43. Dinis PB, Martins ML, Subtil J: Does Helicobacter pylori play a role in upper respiratory tract inflammation? A case report. Ear Nose Throat J. 2005; 84(4):238-40.

44. Jelavic B, Grgić M, Cupić H, Kordić M, Vasilj M, Baudoin T: Prognostic value of Helicobacter pylori sinonasal colonization for efficacy of endoscopic sinus surgery. Eur Arch Otorhinolaryngol. 2012; 269(10):2197-202. 